\title{
Career focus
}

\section{Clinical pharmacology}

Nick Bateman and Simon Maxwell look at the mind expanding world of new drugs

Clinical pharmacology and therapeutics is a relatively young specialty borne out of the rapidly increasing contribution that drug treatments have made to medical practice in the second half of the century. This, in turn, has been driven by a thriving pharmaceutical industry, much of which is UK based. Its development has been underpinned by the recognition that newly available drugs must be assessed in unbiased controlled clinical trials designed, conducted, and analysed to the highest possible standards. Meanwhile, improved measurement techniques of both drugs and their metabolites, and the body's response to them, have increased understanding of pharmacokinetics and pharmacodynamics. Understanding of the potential mechanisms of drug action has increased, increasing the number of target sites for new drug development. Drugs are also used as tools to understand physiological and pathophysiological processes.

The arrival of molecular genetics with mapping of the human genome is set to revolutionise the specialty in the next century. The latest scientific techniques will lead to the discovery of many hitherto unknown target sites and, subsequently, to the design of specific drugs modelled to interact with them. Doctors can expect new, highly specific drugs to progressively replace the blunter pharmacological approaches of past decades. The next generation of clinical pharmacologists will be involved in developing methods to measure the effects of these new drugs in patients.

\footnotetext{
A broad church

Training in clinical pharmacology provides the opportunity to develop a career in many different areas of medical practice, with all clinical pharmacologists sharing the traits of enthusiasm and expertise in the development, evaluation, and use of drugs. As well as practising medicine in the NHS, clinical phar-
}

\section{Roles of the clinical pharmacologist}

\section{In the NHS}

- Physician (general internal medicine or specialty)

- Poisons information services

- Formulary development

- Prescribing adviser (trusts, health authorities)

- Ethics committee

- Drug and therapeutics committees

- Adverse event reporting

University

- Clinical research

- Pharmacovigilance

- Pharmacoeconomics

- Teaching

Pharmaceutical Industry

- Clinical trials (phase I and IIa)

Other activities

- Drug regulation (Medicines Control Agency/Committee on Safety of Medicines)

- Involvement in publications such as British National Formulary, Prescriber's Journal, and Drug and Therapeutics Bulletin.

- Involvement in NICE (or SHTAC in Scotland)

macologists also fulfil a wide variety of other roles (see box).

\section{In the NHS}

Traditionally, clinical pharmacologists have combined their specialist interest with a commitment to general internal medicine, usually in a teaching hospital. However, the future may see an alignment of training in clinical pharmacology with other organ based specialties so that the unique background and skills of the clinical pharmacologist can be brought into these areas. New opportunities for joint training in clinical pharmacology and specialties such as paediatrics and psychiatry, as well as the more traditional alignments such as cardiology and respiratory medicine, will therefore be possible.

The NHS now spends over $£ 5000 \mathrm{~m}$ a year on drug products and is under increasing pressure to spend more as newer agents become available, creating a pressing need for drug budgets to be used efficiently and cost effectively. Clinical pharmacologists are likely to play an increasing role in influencing drug use. A recent report recommended joint appointments between health authorities and trusts of consultants whose prime responsibility would be to assist them in developing rational prescribing policies and drug formularies and controlling drug budgets. ${ }^{1}$ The importance of these initiatives has been recognised in the setting up of National Institute for Clinical Excellence (NICE) in England and Wales (SHTAC in Scotland), to which clinical pharmacologists are already making important contributions.

A second major role in the NHS is in clinical toxicology. The six centres of the National Poisons Information Service are all headed by clinical pharmacologists. The service is likely to recruit more consultant staff as its role changes after a review of its role by the UK health departments.

A third role for clinical pharmacologists is in the recording and analysis of adverse drug reactions involving registered and commercially available drugs (pharmacovigilance). This is carried out in the regional monitoring centres established in collaboration with the Committee on Safety of Medicines in
Birmingham, Cardiff, Liverpool, and Newcastle. Other important areas of activity include involvement in hospital drug and therapeutics committees and local research ethics committees.

In universities

Clinical pharmacology is predominantly an academic specialty, with most consultants working in a medical school. In this setting NHS clinical commitments are often combined with a strong academic research programme addressing drug related issues. Most clinical pharmacologists also contribute to teaching in medical schools. In the years before house officers and senior house officers learn to use an endoscope or bronchoscope their main specialty is clinical pharmacology, the safe and effective use of drugs. For this reason, clinical pharmacologists will continue to have a vital role in undergraduate education, and in future an increasing role in continuing medical education, as the provision of postgraduate education independent of industry sponsorship is developed.

Pharmaceutical industry

The pharmaceutical industry is currently Britain's most successful export industry and offers an attractive and well paid career for motivated individuals. Although it has been traditional for many doctors to enter after MRCP and some early clinical experience, it is increasingly apparent that there is a lack of individuals with appropriate clinical pharmacology training. Clinical pharmacologists in the industry work with research scientists and toxicologists in selecting new drugs to test in humans and are responsible for the design and execution of phase I clinical studies in healthy volunteers. They also work closely with clinical research physicians in developing larger multicentre phase Ilb and III trials. Increasingly, pharmaceutical companies are encouraging their clinical pharmacologists to take up honorary 


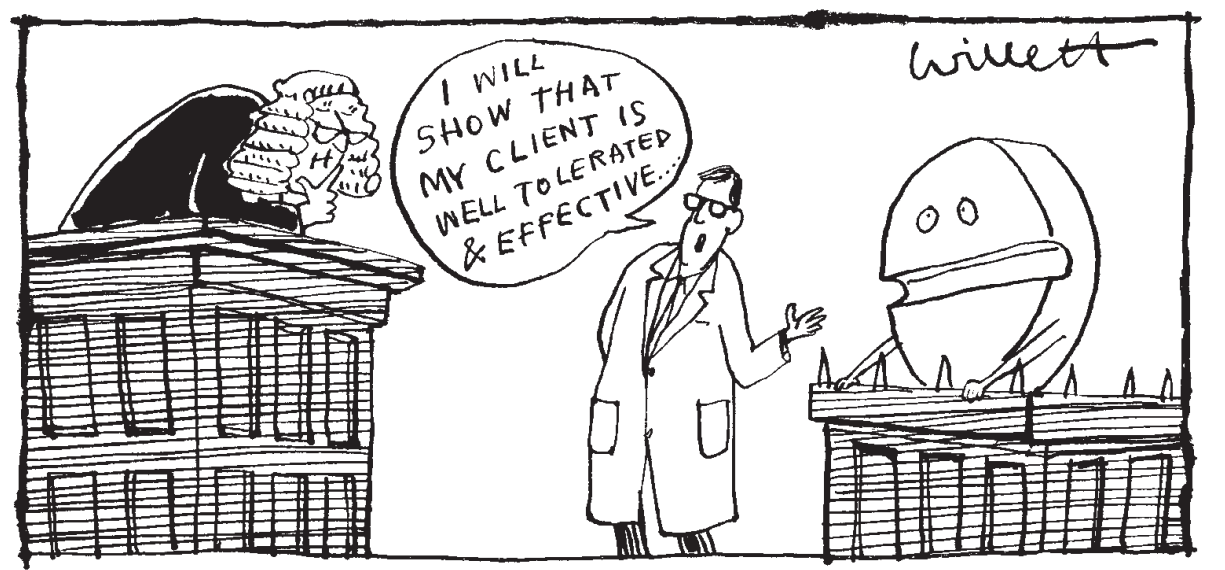

clinical appointments if possible. A trend towards increasing cooperation between the industry and academic departments is likely and is already successfully operating in other European countries.

\section{Other activities}

Drug regulation in Britain is the responsibility of the Medicines Control Agency. Physicians working for regulatory authorities require a sound knowledge of clinical pharmacology in order to assess the quality of drug applications for licensing, and many are clinical pharmacologists. They hold governmental positions and deal with all aspects of new drug development, from pharmacology to toxicology to assessment of safety and efficacy. Senior clinical pharmacologists working in the NHS and academia are asked to serve on drug licensing committees, such as the Medicines Commission and the Committee on Safety of Medicines.

\section{Training requirements}

The primary attributes for a career in clinical pharmacology are enthusiasm to develop drugs, monitor their effects, apply them to clinical situations for benefit, and ensure that your peers use them safely and appropriately. Clinical pharmacologists need to adapt to multiple challenges, from designing trials for assessing new drugs to dealing with ethical dilemmas and the legal aspects of drug regulation. Clinical pharmacologists are generally active and energetic individuals who enjoy being challenged and prefer to find answers to questions themselves rather than wait to be told.

Many young doctors will already have expressed an interest in research by taking an intercalated BSc. Applicants for higher medical training in clinical pharmacology will have completed general professional training and gained the MRCP. Entry into training does not necessitate prior research experience or publication: that is an integral feature of the training programme. Most trainees will enter a joint training programme comprising clinical pharmacology and another specialty, usually general internal medicine, which lasts for five years. Trainees will gain methodological experience of clinical and laboratory research techniques of particular relevance to clinical pharmacology. The training programme includes a year of supervised research, but many trainees, particularly those wishing to pursue academic careers, undertake a two or three year fellowship sponsored by the MRC or a major charity towards an $\mathrm{MD}$ or $\mathrm{PhD}$.

\section{Developments in training}

More recently, it has been recognised that trainees may wish to combine training in clinical pharmacology and another specialty. They can now achieve this in two ways. Firstly, they can combine clinical pharmacology with both general internal medicine and another organ based specialty such as cardiology, and a seven year training programme has been recognised. Secondly, they can combine clinical pharmacology training with a specialty interest such as paediatrics or psychiatry, for which a five year training programme is the norm. Individuals completing these programmes will be able to apply a firm grounding in clinical pharmacology to understanding drug action and then apply this in their chosen organ based specialty.

The need to develop effica- cious drugs and pressure to introduce them into clinical practice has led to the recognition that more well trained clinical pharmacologists are needed in the NHS, academia, and industry. Responding to this need, the Association of the British Pharmaceutical Industry (ABPI) and the NHS established a new initiative in 1996 to jointly fund training posts in clinical pharmacology. There are now over 20 individuals in these new posts and new posts are created each year. Those who gain their CCSTs will be well positioned to have a major future role in developing therapeutic strategies in the NHS or working in drug development in the pharmaceutical industry. In the future join appointments between industry and academic departments at consultant level may make this distinction less clear cut.

\section{How to get started}

Anyone wishing to learn more about a possible career in clinical pharmacology should first make contact with a local department. There are clinical pharmacologists in almost all UK medical schools. Alternatively, they can contact the British Pharmacological Society Clinical Section, which is the academic society for UK clinical pharmacologists.

Nick Bateman, consultant toxicologist, Royal Infirmary of Edinburgh, Simon Maxwell, senior lecturer in clinical pharmacology, University of Edinburgh

1 Clinical pharmacology and therapeutics in a changing world. London: Royal College of Physicians, 1999

Further information Section, 16 Angel Gate, City Road, London EC1V 2PT. Tel: 0171417 0111/2/3

- Association of the British Pharmaceutical Industry, Dr Richard Tiner, Medical Director, 12 Whitehall, London SW1A 2DY. Tel: 01717471404
- British Pharmacological Society, Clinica
Briefing

- Many doctors may contemplate a spell in the armed forces, but it certainly isn't for everyone, as a recent ruling in the European Court of Human Rights made clear (IDS Brief 1999;647:2-4). The court ruled that the British armed forces' policy of discharging homosexual personnel was a breach of their right to respect for a private life (article 8 of the code, www.hmso.gov.uk/ acts/acts 1998/19980042.htm). The judgment is also likely to have a far-reaching impact on employment law in other public sector organisations. The 1998 Human Rights Act requires courts and tribunals to interpret the European Convention on Human Rights "so far as it is possible to do."

- The long hours culture is firmly established in much of the UK workforce, but the causes for such attitudes are not as simple as we might think. A survey of 823 British people who worked more than 48 hours each week found that almost half did so voluntarilybecause they love their work and do it as a hobby. Earning more money was a motivating factor in about a quarter of respondents. (IRS Employment Trends 1999;689:3). Very few worked long hours because their employer expected it, or for fear of the sack. And working long hours seemed not to have an adverse effect on self reported family life, though friendships may suffer, and work performance be undermined. The finding has implications for the implementation of the Working Time Directive: the government is currently "simplifying" the regulations to mean that working time is only calculated from the portion of work that is "measured or pre-determined by the employer." Still, there doesn't seem to be any reason why you can't both enjoy your work and bill for it.

Career focus is edited by Douglas Carnall,

BMJ, BMA House, Tavistock Square, London WC1H 9JR

Tel: 01713874499

Fax: 01713836418

dcarnall@bmj.com or send the

command subscribe career-f to

listserv@listserv.bma.org.uk

Archived at http://classified.bmj.com 